\title{
NEIGHBORHOOD ANALYSES OF CANOPY TREE COMPETITION ALONG ENVIRONMENTAL GRADIENTS IN NEW ENGLAND FORESTS
}

\author{
Charles D. Canham, ${ }^{1,5}$ Michael J. Papaik, ${ }^{1}$ María Uriarte, ${ }^{1}$ William H. McWilliams, ${ }^{2}$ Jennifer C. Jenkins, ${ }^{3}$ \\ AND Mark J. Twery ${ }^{4}$ \\ ${ }^{1}$ Institute of Ecosystem Studies, Box AB, Millbrook, New York 12545 USA \\ ${ }^{2}$ USDA Forest Service, Forest Inventory and Analysis, 11 Campus Blvd., Suite 200, \\ Newtown Square, Pennsylvania 19073 USA \\ ${ }^{3}$ Rubenstein School of Environment and Natural Resources, University of Vermont, \\ 590 Main St., Burlington, Vermont 05405 USA \\ ${ }^{4}$ USDA Forest Service, PO Box 968, Burlington, Vermont 05402 USA
}

\begin{abstract}
We use permanent-plot data from the USDA Forest Service's Forest Inventory and Analysis (FIA) program for an analysis of the effects of competition on tree growth along environmental gradients for the 14 most abundant tree species in forests of northern New England, USA. Our analysis estimates actual growth for each individual tree of a given species as a function of average potential diameter growth modified by three sets of scalars that quantify the effects on growth of (1) initial target tree size (dbh), (2) local environmental conditions, and (3) crowding by neighboring trees. Potential growth of seven of the 14 species varied along at least one of the two environmental axes identified by an ordination of relative abundance of species in plots. The relative abundances of a number of species were significantly displaced from sites where they showed maximum potential growth. In all of these cases, abundance was displaced to the more resource-poor end of the environmental gradient (either low fertility or low moisture). The pattern was most pronounced among early successional species, whereas late-successional species reached their greatest abundance on sites where they also showed the highest growth in the absence of competition. The analysis also provides empirical estimates of the strength of intraspecific and interspecific competitive effects of neighbors. For all but one of the species, our results led us to reject the hypothesis that all species of competitors have equivalent effects on a target species. Most of the individual pairwise interactions were strongly asymmetric. There was a clear competitive hierarchy among the four most shade-tolerant species, and a separate competitive hierarchy among the shade-intolerant species. Our results suggest that timber yield following selective logging will vary dramatically depending on the configuration of the residual canopy, because of interspecific variation in the magnitude of both the competitive effects of different species of neighbors and the competitive responses of different species of target trees to neighbors. The matrix of competition coefficients suggests that there may be clear benefits in managing for specific mixtures of species within local neighborhoods within stands.
\end{abstract}

Key words: competition; environmental gradients; Forest Inventory and Analysis; fundamental niche; neighborhood analyses; New England (USA) forests; realized niche; spatially explicit models; temperate forests; tree competition.

\section{INTRODUCTION}

Understanding the nature of competitive interactions among forest trees is central to our understanding of forest community organization and dynamics. This knowledge is also critical to the development of sustainable management of forest ecosystems, particularly in mixed-species, uneven-aged stands. Silviculture in the northeastern U.S. has seen a dramatic shift away from even-aged management and clear-cutting to partial harvesting and all-aged management (USDA Forest Service 2001). Landowners and foresters now routinely manage for complex residual structure in northeastern

Manuscript received 12 July 2004; revised 27 April 2005; accepted 6 May 2005. Corresponding Editor: S. L. Brown.

${ }^{5}$ E-mail: ccanham@ecostudies.org forests. This presents a host of new scientific challenges. The spatial pattern of a partial harvest will have important implications for understory light levels for regeneration (e.g., Canham et al. 1999, Beaudet et al. 2002), including the potential for invasion by exotic species (Knapp and Canham 2000). Given the relatively limited dispersal distances of most northeastern tree species (Ribbens et al. 1994, Clark et al. 1999), the spatial distribution of seed trees will have strong effects on the distribution and abundance of regeneration. Perhaps most important from an economic standpoint, the spatial pattern of a harvest determines the degree of release from competition among residual trees, with potentially dramatic effects on growth and survival of residual trees (e.g., Wimberly and Bare 1996, Berger and 
Hildenbrandt 2000, He and Duncan 2000, Coates et al. 2003, Canham et al. 2004).

The long life spans and large adult sizes of forest trees usually have precluded experimental approaches to the study of tree competition except among juveniles (seedlings and saplings). Forest ecologists typically have approached the study of the competitive effects of adult trees through one of two alternate approaches. The more mechanistic of the alternatives has been to focus on competition for a particular resource and to decompose the analysis into separate studies of (1) the effects of trees on the availability of the resource (i.e., light extinction by tree canopies, e.g., Canham et al. [1994]) and (2) the responses of individuals to the altered availability of the resource (e.g., Pacala et al. 1994, Kobe et al. 1995). A more phenomenological and more widely applicable approach has been to use regression analysis of the growth and survival of individuals as a function of the distribution and abundance of neighbors (e.g., Bella 1971, Lorimer 1983, Biging and Dobbertin 1992, 1995, He and Duncan 2000, Canham et al. 2004, Uriarte et al. $2004 a, b$ ). This latter approach reflects the mechanistic link between the abundance, size, and spatial distribution of neighboring trees and the strength of both aboveground and belowground competition (Larocque 2002, Canham et al. 2004).

It is often assumed that differences in relative abundance of species are at least partly a reflection of competitive hierarchies (e.g., Howard and Goldberg 2001), with the dominant competitor being defined either in terms of the strongest competitive effects on neighbors or the least competitive response to neighbors (Goldberg 1990, Goldberg and Landa 1991). Hubbell (2001) has challenged this notion and has argued that interspecific differences in the competitive effects are relatively unimportant in explaining patterns of diversity and relative abundance in forests. This debate has highlighted the scarcity of robust empirical estimates of interspecific competition coefficients, i.e., the per capita effect of one species on another (Freckleton and Watkinson 2001). There also has been a long-running debate over the degree to which competition plays a central role in niche partitioning and the distribution of tree species along environmental gradients (Whittaker 1975, Keddy 1989, Bigelow and Canham 2002), with much of the research being focused on early life history stages (e.g., the regeneration niche of Grubb [1977]). Analyses of the effects of competition on the distribution and abundance of tree species at a landscape scale are quite rare, however. Given that all of the methods currently used to assess competition among forest trees require extensive data from within any given site, it is perhaps not surprising that there have been few studies with sufficient data to address these questions along regional environmental gradients.

Regional networks of permanent plots established for forest inventory purposes provide one potential source of suitable data. The USDA Forest Service Forest
Inventory and Analysis (FIA) program maintains an extensive network of long-term permanent plots within all of the forested regions of the U.S. FIA data are collected primarily for purposes of forest inventory, but have proven useful for a variety of ecological analyses (e.g., Caspersen et al. 2000, Jenkins et al. 2001, Goodale et al. 2002). The network of plots is effectively a random sample stratified by land cover. Inventory cycles have typically been $10-15$ years. Although inventory methodology is now being standardized nationwide, there are differences in methodology for earlier censuses among states and time periods, and not all plots from one census were remeasured in the next census. The locations of adult trees within plots are recorded primarily as a means of locating the trees for remeasurement in future censuses. The location data, however, are invaluable for the neighborhood analyses of tree growth and survival presented here.

In this paper, we use FIA data from the most recent census interval for the states of Vermont and New Hampshire to analyze the effects of competition on canopy tree growth for the 14 most abundant tree species in the region. One of the reasons for selecting the states of Vermont and New Hampshire was the similarity in timing and methods of recent FIA censuses. Our analysis is based on recently developed, spatially explicit analyses of canopy tree competition (Canham et al. 2004, Uriarte et al. 2004a, b), and uses likelihood methods and model selection as an alternative to traditional hypothesis testing (Johnson and Omland 2004, Canham and Uriarte 2006). In addition, we use an ordination of relative abundance of tree species in the network of 1249 plots distributed throughout the two states as the basis for an indirect analysis of the major environmental gradients in the region. Our analysis of growth of each of the 14 "target" tree species estimates growth for each individual tree of a given species as a function of the average potential diameter growth (in millimeters per year), and three sets of scalar modifiers ranging from 0 to 1 that quantify the effects on average potential growth of (1) initial target tree size (dbh, in centimeters); (2) local environmental conditions (as defined by plot scores on the first two axes of the ordination, outlined in detail in Methods); and (3) crowding by neighboring trees. As part of (3), the analysis provides empirical estimates of the strength of intraspecific and interspecific competitive effects of neighbors.

Our results address a number of fundamental questions about the nature of competition within this guild of species. (1) Are different species of neighboring trees functionally equivalent competitors? (2) Do species reach their greatest relative abundance (realized niche) in the sites in which they also have the greatest growth in the absence of competition (fundamental niche), or are their realized niches significantly displaced due to competition? (3) Is the strength of interspecific competition between pairs of species related to similarity of 
distribution of the species along environmental gradients, i.e., does the strength of competition increase with similarity of environmental requirements? Our analyses are specifically designed to be incorporated in a spatially explicit model of forest dynamics (SORTIE; Pacala et al. 1996), so that we can fully explore the implications of managing for structural heterogeneity in forest ecosystems, particularly in uneven-aged stands (Harvey et al. 2002, Mitchell and Beese 2002, Coates et al. 2003).

\section{Methods}

\section{FIA data for Vermont and New Hampshire}

The most recent censuses for Vermont and New Hampshire were conducted between April 1996 and August 1998, whereas the previous censuses were conducted between March 1982 and November 1983. There were 1249 plots in the two states that had been measured in both census intervals and that were in forested land-use categories. Essentially all of the forests were of natural origin (not plantations). There was evidence of harvesting during the census period in approximately one-third (447) of these plots. We omitted these plots from the growth analysis for two reasons: logging would have significantly altered the competitive environment at an unknown time during the census interval; and, more importantly, logging selectively removes particular tree species. This would result in biased underestimates of the competitive effects of the harvested species, because we based our assessment of the competitive neighborhood on the structure and composition of the neighborhood at the beginning of the census interval. Thus, the growth analyses were based on a total of 802 plots, roughly evenly distributed across the two states.

The 1982-1983 censuses used a single circular plot that was either $14.90 \mathrm{~m}$ ( $86 \%$ of the plots) or $16.07 \mathrm{~m}$ in radius ( $1 / 6$ acre or $1 / 5$ acre in area, respectively). The 1996-1998 censuses were conducted under a new plot design that uses four $7.32 \mathrm{~m}$ radius subplots instead of one large central plot. One of the new subplots is centered over the original, larger plot. Within the new subplot, all trees $>12.7 \mathrm{~cm}$ dbh were remeasured in the 1996-1998 census. In the remainder of the original plot, only saw-timber-sized trees $(>22.86 \mathrm{~cm} \mathrm{dbh})$ were censused. For two reasons, we have limited our analyses of growth to trees $>12.7 \mathrm{~cm} \mathrm{dbh}$ that were present within a $7.32 \mathrm{~m}$ radius of the center of the original plot at the time of the 1980s censuses ("target trees"): (1) we have data on dbh at the beginning of the census interval for all of these stems (and can, therefore, calculate growth rates for those individuals), and (2) by limiting the analysis to stems in the smaller, new subplot, we have a full census of all neighbors $>12.7 \mathrm{~cm}$ dbh present at the beginning of the census interval in a minimum radius of $7.58 \mathrm{~m}$ around each target tree. Diameter growth of each target tree (in millimeters per year) between the two censuses was calculated by dividing the total increase in dbh (in millimeters) by the number of growing seasons between the two census dates for a given plot.

\section{Characterization of environmental variation among plots using detrended correspondence analysis}

Limiting our analysis to the states of Vermont and New Hampshire also allowed us to minimize variation in climate and land-use history. The vast majority of the forests within these two states fall within the broadly defined mixed-conifer-northern hardwood forests of northern New England. Nonetheless, there is clearly important variation among the plots in a wide range of environmental factors. FIA field methods include a variety of visual assessments of site conditions within plots, but there are no direct measures of soils and climatic variables. Instead, we used a detrended correspondence analysis, DCA (Hill 1979), based on the relative abundance of tree species within plots, to indirectly characterize environmental variation between plots. DCA has been criticized for its potential to distort underlying gradients in the resulting ordination space, but our initial tests with the algorithm revealed welldistributed plots within ordination space. With the most recent census data for the full set of 1249 plots, we used the implementation of DCA in the R software package (available online). ${ }^{6}$ Use of the full data set (rather than the subset of 802 unlogged plots) minimized the potential for outliers to influence the analysis. DCA produces sets of ordination scores for both the samples (plots) and the centroids of species abundance along the ordination axes. In effect, we use the variation in relative abundance of species among plots to provide an indirect measure of site conditions in each plot, and then use the ordination scores for a particular plot in our regression analysis that attempts to explain variation in absolute growth of trees within and among plots.

\section{A maximum likelihood analysis of tree growth}

We conducted separate analyses of diameter growth for each of the 14 most common species of trees in the 802 unlogged plots in the data set (Table 1). As noted previously, our analysis of growth of each of these "target" tree species estimates four terms: (1) average potential diameter growth (PDG, in millimeters per year), and three sets of scalar modifiers ranging from 0 to 1 that quantify the effects on average potential growth of (2) initial target tree size (dbh, in centimeters), (3) local environmental (site) conditions, and (4) crowding by neighboring trees:

$$
\begin{aligned}
\text { Growth }= & \text { PDG } \times \text { Size effect } \times \text { Site effect } \\
& \times \text { Crowding effect. }
\end{aligned}
$$

Potential diameter growth (PDG) in this model is the expected growth of a tree when the other three factors

\footnotetext{
${ }^{6}\langle$ http://www.r-project.org/ $\rangle$
} 
TABLE 1. Median and maximum dbh of trees $>12.7 \mathrm{~cm}$ dbh for the 14 target tree species in the 802 plots from the original (1980s) census used in the analysis.

\begin{tabular}{|c|c|c|c|c|}
\hline Species & Common name & Acronym & Median dbh (cm) & Maximum dbh $(\mathrm{cm})$ \\
\hline Abies balsamea & balsam fir & ABBA & 19.1 & 45.0 \\
\hline Acer rubrum & red maple & ACRU & 23.6 & 66.0 \\
\hline Acer saccharum & sugar maple & ACSA & 28.4 & 99.3 \\
\hline Betula alleghaniensis & yellow birch & BEAL & 29.0 & 83.3 \\
\hline Betula lenta & black birch & BELE & 21.2 & 53.6 \\
\hline Betula papyrifera & paper birch & BEPA & 22.4 & 56.9 \\
\hline Fagus grandifolia & American beech & FAGR & 28.2 & 70.4 \\
\hline Fraxinus americana & white ash & FRAM & 27.2 & 83.1 \\
\hline Picea rubens & red spruce & PIRU & 23.6 & 66.0 \\
\hline Pinus strobus & eastern white pine & PIST & 25.9 & 116.8 \\
\hline Populus tremuloides & trembling aspen & POTR & 23.7 & 45.0 \\
\hline Prunus serotina & black cherry & PRSE & 24.9 & 45.4 \\
\hline Quercus rubra & red oak & QURU & 28.7 & 97.3 \\
\hline Tsuga canadensis & eastern hemlock & TSCA & 25.1 & 67.3 \\
\hline
\end{tabular}

are at optimal values (1), i.e., at optimal size, on the optimal site, and with no crowding.

We use a lognormal function for the shape of the size effect:

$$
\text { Size effect }=\exp \left[-\frac{1}{2}\left(\frac{\ln (\mathrm{dbh} / \delta)}{\sigma}\right)^{2}\right]
$$

where $\delta$ is the dbh (of the target tree) at which PDG occurs, and $\sigma$ determines the breadth of the function. This functional form is flexible enough that, for the effective range of adult trees, the shape may be monotonically increasing (i.e., when $\delta$ is very large), decreasing (i.e., when $\delta$ is very small), or may have a single "hump" and a skew to the left when $\delta$ is within the normal range of dbh (Canham et al. 2004).

Vegetation theory generally recognizes three alternate models of distribution of species along environmental gradients (Bigelow and Canham 2002). Under fundamental niche differentiation (FND), species segregate because they have optimal performance at different points along a gradient (Curtis 1959, Whittaker 1975). This leads to an expectation of a series of Gaussian ("bell-shaped") distributions with different modes along the gradient (Gauch 1982). Under Keddy's (1989) shifting competitive hierarchy $(\mathrm{SCH})$, all species have physiological optima at the upper end of resource gradients, but may be displaced to suboptimal locations by competition. Under this model, potential growth (i.e., in the absence of competition) should rise monotonically and asymptotically for all species along a resource gradient. A logistic function provides a suitable form for this hypothesized relationship. The continuum concept (CC) of Austin and Smith (1989) combines elements of both FND and SCH, depending on the nature of the gradients (whether a depletable resource or a nondepletable environmental factor such as temperature).

We used the first two axes of our DCA ordination of the vegetation data as independent (orthogonal) measures of variation along environmental gradients. We used these ordination scores to explore the relationship (if any) between growth of trees in a plot and variation in the ordination scores for that plot. We compared two functional forms of the potential relationships between the ordination scores and growth to discriminate between fundamental niche differentiation (FND) and shifting competitive hierarchies $(\mathrm{SCH})$ as explanations for the distribution of species performance along the ordination axes. The first functional form was the bivariate Gaussian:

$$
\begin{aligned}
& \text { Site effect } \\
& \qquad=\exp \left(-\frac{1}{2}\left[\left(\frac{\mathrm{Axis} 1_{i}-X 1_{0}}{X 1_{\mathrm{b}}}\right)^{2}+\left(\frac{\mathrm{Axis} 2_{i}-X 2_{0}}{X 2_{\mathrm{b}}}\right)^{2}\right]\right)
\end{aligned}
$$

where Axis $1_{i}$ and $\mathrm{Axis}_{i}$ are the observed ordination axis scores for plot $i ; X 1_{0}$ and $X 2_{0}$ are the estimated axis 1 and 2 scores, respectively, at which maximum potential growth occurs; and $X 1_{\mathrm{b}}$ and $X 2_{\mathrm{b}}$ are estimated parameters that control the breadth of the function (i.e., the variance of the normal distribution). Eq. 3 produces the classic Gaussian distribution of species performance along an environmental axis predicted by FND (Curtis 1959, Whittaker 1975, Gauch 1982), but can also produce sigmoidal, monotonic curves (as predicted by $\mathrm{SCH}$ ) within restricted ranges of either axis.

We also fit models using a bivariate logistic equation of the following form:

$$
\text { Site effect }=\left[\frac{1}{\left(1+\frac{\text { Axis1 }_{i}^{\prime}}{X 1_{0}}\right)^{X 1_{\mathrm{b}}}}\right]\left[\frac{1}{\left(1+\frac{\text { Axis2 }}{X 2_{0}^{\prime}}\right)^{X 2_{\mathrm{b}}}}\right]
$$

where all of the terms are as defined for Eq. 3, except that the original axis scores have been rescaled to be greater than zero by adding the minimum axis score plus 0.1 to each value. This forces the function to be either monotonically increasing (when $X 1_{\mathrm{b}}$ and $X 2_{\mathrm{b}}$ are negative) or monotonically decreasing (when $X 1_{\mathrm{b}}$ and $X 2_{\mathrm{b}}$ are positive) (as predicted by $\mathrm{SCH}$, if the ordination axis reflects a positive or negative association, respec- 
tively, with resource availability). This functional form produces sigmoidal variation in growth along either or both axes, in which $X 1_{0}$ and $X 2_{0}$ define the points at which growth is half of the maximum potential value (PDG). The shape of the logistic curve is more flexible than the Gaussian function in the steepness of the inflection of the curve. For both Eqs. 3 and 4, we also tested univariate functions in which terms for one of the two axes were dropped from the analysis if initial results indicated that there was no response of a target species to that axis.

Our analysis of the effects of crowding follows from the long tradition of distance-dependent analyses of competition in which competitive effects are assumed to vary as a function of the sizes of, and distances to, neighboring trees (e.g., Bella 1971, Hegyi 1974, Lorimer 1983, Wimberly and Bare 1996, Wagner and Radosevich 1998, Vettenranta 1999, Berger and Hildenbrandt 2000, Canham et al. 2004, Uriarte et al. 2004a, b). The net effect of a neighboring tree on the growth of a target tree of a given species is assumed to vary as a direct function of the size (dbh) of the neighbor, and as an inverse function of the distance to the neighbor. Most previous studies have assumed that all species of competitors are equivalent. In our analysis, the net effect of an individual neighbor is multiplied by a species-specific competition index $\left(\lambda_{i, z}\right)$ that ranges from 0 to 1 and allows for differences among neighboring species $i$ in their competitive effect on the target tree of species $z$. Then, for $i=1, \ldots, s$ species and $j=1, \ldots, n$ neighbors of species $i$ within a radius $(R)$ of the target tree $z$, a Neighborhood Competition Index, NCI (Canham et al. 2004), specifying the net competitive effect of the neighbors on the target tree, is given by

$$
\mathrm{NCI}=\sum_{i=1}^{s} \sum_{j=1}^{n} \lambda_{i, z} \frac{\left(\operatorname{dbh}_{i j}\right)^{\alpha}}{\left(\text { distance }_{i j}\right)^{\beta}}
$$

where $\alpha$ and $\beta$ are estimated by the analyses (rather than set arbitrarily as in previous studies), and determine the effect of the dbh and the distance to the neighbor, respectively, on NCI for the target tree. Because juvenile trees are only censused in a small subplot within each plot, only adult trees (stems $>12.7 \mathrm{~cm}$ dbh) are tallied in the calculation of NCI. We only included trees within a fixed radius $(R)$ of $7.58 \mathrm{~m}$, because this was the maximum distance allowed by plot size within which we had an uncensored sample of all adult trees within that distance.

To keep the number of parameters in the model manageable, $\alpha$ and $\beta$ are assumed to be similar for all species of neighbors. To facilitate comparisons of the species-specific competition indices $\left(\lambda_{i, z}\right)$ across different species of target trees, the values of $\lambda_{i, z}$ for each species or group of competitors are rescaled as a fraction of the highest $\lambda_{i, z}$ (i.e., $\lambda_{i, z}$ for the species or group of competitors with the strongest competitive effect on the target tree species is fixed at 1).
We assume that growth declines monotonically as $\mathrm{NCI}$ increases, using the functional form:

$$
\text { Crowding effect }=\exp \left[-C(\mathrm{NCI})^{D}\right] .
$$

If $D=1$, this is a traditional negative exponential function. If $D>1$, the function is sigmoidal, with an initially slow rate of decline as NCI increases, followed by a steeper rate of decline. In order to facilitate comparisons of the effects of crowding across different species of target trees, we computed a relative value for $\mathrm{NCI}$ for each analysis of a target species to scale it in the range from 0 to 1 by dividing NCI calculated for each target tree by the maximum value of NCI for any target tree of that species. We did this primarily to facilitate comparison among species in the interpretation of results.

We also tested a variant of Eq. 6 in which the effect of crowding on target tree growth varied as a function of target tree dbh. This effect is independent of the underlying effect of target tree size on potential growth (size effect, in the absence of competition). This allowed us to test whether a given level of crowding had a greater effect on smaller (or larger) target trees (Canham et al. 2004). To test this, we allowed the exponential decay term $(C)$ in Eq. 6 to vary as a function of target tree size (dbh):

$$
C=C^{\prime}\left(\mathrm{dbh}^{\gamma}\right) .
$$

If $\gamma=0$, there is no variation in sensitivity to crowding as a function of target tree size. If $\gamma<0$, then sensitivity to crowding declines as target tree dbh increases (i.e., smaller trees suffer a greater reduction in growth from a given level of crowding than do larger trees). If $\gamma>0$, then larger trees are more sensitive to a given level of crowding than smaller trees.

For each analysis of the growth of a target tree species, the regression model described by Eqs. 2-7 requires estimation of a maximum of $n+11$ parameters for $n$ species or groups of competitors. In principle, with sufficient data our method could estimate all of the pairwise competition coefficients $\left(\lambda_{i, z}\right)$ that quantify the per capita effect of a competitor of neighboring species $i$ on target species $z$. In practice, this would require enormous data sets to encounter sufficient numbers of rare species as competitors and to have large enough sample sizes to accommodate the very large number of parameters in the model. Our approach to this challenge is dictated by both practical and theoretical considerations. We first calculated the numbers of neighbors of different species around target trees of each of the 14 study species. We then defined a "full" set of competitors (unique for each different target tree species) using separate $\lambda_{i, z}$ for each species of competitor for which there were $>100$ neighbors (summed across all target trees) in the data set. All remaining species of neighbors for that target species were then grouped into an "other species" group. We compared this "full" model with three alternate groupings of competitors: (1) an "equiv- 
alent competitors" model in which all species of competitors had equivalent per capita effects (i.e., $\lambda_{i, z}$ $=1$ for all species of neighbors); (2) an "intraspecific vs. interspecific" model that estimated separate $\lambda_{i, z}$ for intraspecific competition and interspecific competition (treating all heterospecific neighbors as one group); and (3) a "group" model with four different values of $\lambda_{i, z}$ : one for intraspecific competitors, and three separate values for species with low, medium, and high per capita competitive effects. Species were grouped into these three categories based on the estimated $\lambda_{i, z}$ for the species in the "full" model, with low $=0-0.33$, medium $=$ $0.33-0.66$, and high $=0.66-1$. One of the distinct strengths of our approach is that it allows us to make quantitative estimates of the competition coefficients and to explicitly test the hypothesis that the competition coefficients vary among at least some groupings of species.

\section{Parameter estimation, model comparison, and model evaluation}

We solved for the maximum likelihood parameter values of the regression models using simulated annealing (Goffe et al. 1994), a global optimization procedure. The analyses were done using software written specifically for this study using Delphi version 6 for Windows (Borland Software 2000). Residuals were normally distributed, however the variance for many of the species increased with the mean predicted growth rate. Therefore, the error term $\left(\varepsilon_{i}\right)$ for the $i$ th observation (target tree) was modeled using

$$
\varepsilon_{i}=\varepsilon_{0}+\varepsilon_{1} X_{i}
$$

where $X_{i}$ is the predicted value for the $i$ th observation, and $\varepsilon_{0}$ and $\varepsilon_{1}$ are maximum likelihood (ML) estimates. In practice, $\mathrm{ML}$ estimates of $\varepsilon_{0}$ were equal to zero for all 14 species, so variance was a simple linear function of the mean.

The fit of each alternate model was assessed using two metrics. The slope of the regression (with a zero intercept) of observed diameter growth on predicted diameter growth was used to measure bias, with an unbiased model having a slope of 1 . The $R^{2}$ of the regression (1 - SSE/SST) of observed vs. predicted was used as a measure of goodness of fit (SSE, sum of squares error; SST, sum of squares total). Alternate models were compared using the Akaike Information Criterion, AIC (Burnham and Anderson 2002). For some of our target species, the ratio of data points to parameters is $<40$ for the models with the greatest number of parameters; thus we used the corrected AIC $\left(\mathrm{AIC}_{\mathrm{c}}\right)$ for all comparisons, as suggested by Burnham and Anderson (2002). The most parsimonious model is the model with the lowest $\mathrm{AIC}_{\mathrm{c}}$. The absolute magnitude of the differences in $\mathrm{AIC}_{\mathrm{c}}$ between alternate models $\left(\Delta \mathrm{AIC}_{\mathrm{c}}\right)$ provides an objective measure of the strength of empirical support for the competing models (Burnham and Anderson 2002). We used asymptotic two-unit support intervals (Edwards 1992) to assess the strength of evidence for individual maximum likelihood parameter estimates. A two-unit support interval is roughly equivalent to a 95\% support limit defined using a likelihood ratio test (Hilborn and Mangel 1997).

\section{Design constraints in model specification}

Several aspects of our methods were constrained by our objective of developing analyses of adult tree growth that could be incorporated in a spatially explicit, individual-based model of forest dynamics (SORTIE, Pacala et al. [1996]; SORTIE/BC, Coates et al. [2003]). One of the considerations in the specification of the effects of crowding (NCI; Eq. 5) was to use a functional form that could be implemented efficiently in a simulation model. Some of the previous empirical studies of tree competition have used much more elaborate and elegant functions to characterize the potential effects of the spatial configuration of neighbors (e.g., Foli et al. 2003). We also chose to use the configuration of the neighborhood at the time of the initial censuses in 1982-1983 as our estimate of the competitive neighborhood throughout the subsequent census interval. Undoubtedly there were changes in the configuration of the neighborhood during the 12-14 year interval as a result of growth and mortality of neighbors. We can increase the goodness of fit of our models $\left(R^{2}\right)$ by calculating NCI based on an average of conditions at the beginning and end of the census interval. This would give us a false sense of predictive power when applied in a dynamic model like SORTIE, however, because the simulation model is constrained to make predictions of growth during the period from time $t$ to $t+\Delta t$ using information on the state of the system at time $t$ (or earlier, if historical effects of past suppression and release are included; Wright et al. 2000).

\section{Results And Discussion}

\section{Analysis of plot-level variation using DCA}

As would be expected from a sampling scheme designed to provide inventory data for an entire region, the distribution of plot scores was remarkably diffuse within ordination space, rather than clustered into discrete community types (Fig. 1). Based on the autecologies of the component tree species (scientific and common names given in Table 1), the two first axes of the ordination appear to reflect region-wide variation in soil moisture (Axis 1) and soil nutrient status (Axis 2). Axis 2, in particular, appears to reflect variation in soil base saturation and the availability of cations such as calcium and magnesium. Bedrock and soils in the region vary widely in the concentration of these mineral nutrients. The conifer species at the high end of Axis 2 are all well known for their occurrence on very base-rich soils (Fowells 1965). The hardwoods such as sugar maple and white ash in the middle of the axis are also well known for their occurrence on base-rich soils, whereas species such as beech and hemlock at the low 


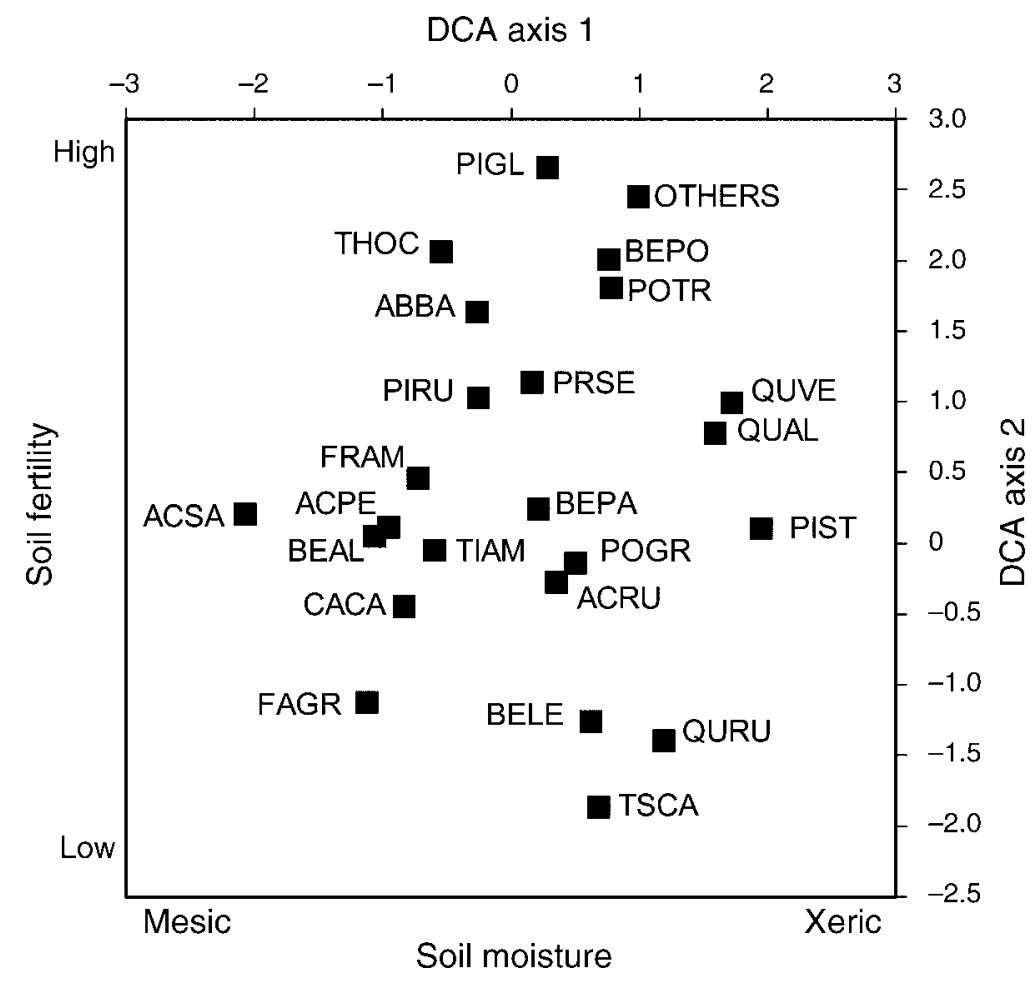

FIG. 1. Locations of species centroids in the DCA ordination of the relative abundance of tree species in 1249 FIA plots for Vermont and New Hampsire, USA. The ordination included the 23 most common species in the data set, as well as rare species grouped as "other." Species names are abbreviated into acronyms using the first 2 letters of the genus and the specific epithet. See Table 1 for the full species names. The interpretation of the first axis as a moisture gradient and the second axis as a soil fertility gradient is based on the autecologies of the component tree species.

end of the axis dominate on more acidic soils derived from parent material low in base cations (Kobe et al. 1995, Kobe 1996, van Breemen et al. 1997).

\section{Variation in potential growth of tree species along environmental gradients}

Seven of the 14 species showed evidence of variation in potential growth along at least one of the first two ordination axes (i.e., models incorporating site effects had lower AIC scores than models omitting those effects; Table 2), and four of the seven showed variation along both axes (Table 2). Our results (Fig. 2) clearly support the concept of fundamental niche differentiation, in which species segregate because they have optimal performance at different points along a gradient (Whittaker 1975), in contrast to the concept of a shifting competitive hierarchy (Keddy 1989), in which all species have physiological optima at the upper end of a resource gradient, but species differ in competitive ability and poorer competitors are displaced to the resource-poor end of a gradient (Bigelow and Canham 2002). Nonetheless, there is also clear evidence that the relative abundance of at least some species is significantly displaced from the sites where they show maximum potential growth (Fig. 3) (as suggested by the shifting competitive hierarchy hypothesis). In all of the cases of displacement, abundance was displaced toward the end of the gradient that we interpret as more resource-poor conditions, either low fertility or low moisture (Fig. 3). The pattern is most pronounced among early- and midsuccessional species such as northern red oak (both axes), red maple (both axes), eastern white pine (Axis 2), and white ash (Axis 2), whereas late-successional, shadetolerant species generally reach their greatest abundance on sites where they also show the highest growth in the absence of competition (Fig. 3).

\section{Effects of tree size on potential growth}

The 14 species showed three different patterns of variation in potential growth as a function of target tree size (Fig. 4). For eight of the species, growth rates either did not vary across the observed size range (i.e., red maple and trembling aspen) or were highest in the smallest size class included in the data set (minimum of $12.7 \mathrm{~cm} \mathrm{dbh}$ ), and declined very slowly with increasing target tree size (i.e., either very small or very large $\delta$ parameters, and $\sigma$ parameters $>4$ ). Four of the tree species (black cherry, white ash, red spruce, and sugar maple) reached a peak of maximum growth in the 30-50 $\mathrm{cm}$ size class range and then showed moderate declines in growth in larger size classes. Finally, two species (paper birch and beech) showed peak potential growth rates at 
TABLE 2. Comparison of alternate models for the 14 target tree species, using AIC corrected for small sample size (AIC $)$.

\begin{tabular}{|c|c|c|c|c|c|c|c|c|c|c|c|}
\hline \multirow[b]{2}{*}{ Species } & \multicolumn{5}{|c|}{$\mathrm{AIC}_{\mathrm{c}}$} & \multirow[b]{2}{*}{ Axis 1} & \multirow[b]{2}{*}{ Axis 2} & \multirow[b]{2}{*}{$\gamma$} & \multirow[b]{2}{*}{ NP } & \multirow[b]{2}{*}{$n$} & \multirow[b]{2}{*}{$R^{2}$} \\
\hline & Full model & Mixed model & Intra. vs inter. & Equiv. comp. & No comp. & & & & & & \\
\hline ABBA & 1437.5 & 1422.3 & 1469.1 & 1465.6 & 1575.8 & & & $\mathrm{Y}$ & 13 & 429 & 0.253 \\
\hline ACRU & 3364.8 & 3339.4 & 3369.0 & 3371.8 & 3422.8 & $\mathrm{G}$ & $\mathrm{G}$ & $\mathrm{Y}$ & 17 & 930 & 0.125 \\
\hline ACSA & 2522.0 & 2495.1 & 2501.1 & 2527.2 & 2696.8 & $\mathrm{G}$ & $\mathrm{G}$ & & 16 & 751 & 0.214 \\
\hline BEAL & 1112.6 & 1105.2 & 1132.7 & 1140.6 & 1157.0 & & & $\mathrm{Y}$ & 13 & 333 & 0.148 \\
\hline BELE & 178.3 & 177.6 & 183.3 & 189.4 & 180.1 & & & & 12 & 55 & 0.268 \\
\hline BEPA & 1423.4 & 1405.1 & 1477.1 & 1500.1 & 1545.9 & & & & 12 & 480 & 0.148 \\
\hline FAGR & 1169.2 & 1153.5 & 1155.6 & 1157.4 & 1192.0 & & $\mathrm{~L}$ & $\mathrm{Y}$ & 15 & 350 & 0.170 \\
\hline FRAM & 510.6 & 489.9 & 489.1 & 490.5 & 493.1 & & G & & 12 & 134 & 0.202 \\
\hline PIRU & 1346.8 & 1341.0 & 1338.3 & 1334.5 & 1429.0 & G & & & 10 & 440 & 0.195 \\
\hline PIST & 2180.8 & 2158.9 & 2188.6 & 2186.8 & 2360.4 & & G & $\mathrm{Y}$ & 15 & 501 & 0.351 \\
\hline POTR & 414.0 & 403.0 & 409.9 & 409.9 & 413.7 & & & $\mathrm{Y}$ & 13 & 104 & 0.232 \\
\hline PRSE & 222.4 & 216.0 & 219.2 & 222.4 & 230.2 & & & & 12 & 53 & 0.228 \\
\hline QURU & 842.6 & 822.9 & 843.2 & 874.2 & 854.0 & G & $\mathrm{L}$ & $\mathrm{Y}$ & 17 & 224 & 0.272 \\
\hline TSCA & 1408.3 & 1391.3 & 1419.1 & 1482.9 & 1575.5 & & $\mathrm{G}$ & $\mathrm{Y}$ & 15 & 425 & 0.284 \\
\hline
\end{tabular}

Notes: Species are identified with acronyms; see Table 1 for full names. The five models vary only in their treatment of competition, including intra- vs. interspecific competition, equivalent competition, and no competition. The "No comp." model incorporates terms for only target tree size and environmental conditions, and ignores the effects of crowding. The best model (lowest $\mathrm{AIC}_{\mathrm{c}}$ ) is indicated in boldface type. Axis 1 and Axis 2 indicate whether the best model included variation along a given axis, and whether the variation was best fit by a Gaussian $(\mathrm{G})$ or logistic (L) function. The " $\gamma$ " column indicates whether (Y, yes; blank, no) the best model also included a term to allow sensitivity to competition to vary with target tree size (Eq. 7). NP is the total number of parameters (including the variance parameters; Eq. 8) in the best model; $n$ is the sample size of target trees; and $R^{2}=1-$ SSE/SST for the relationship between predicted and observed growth.

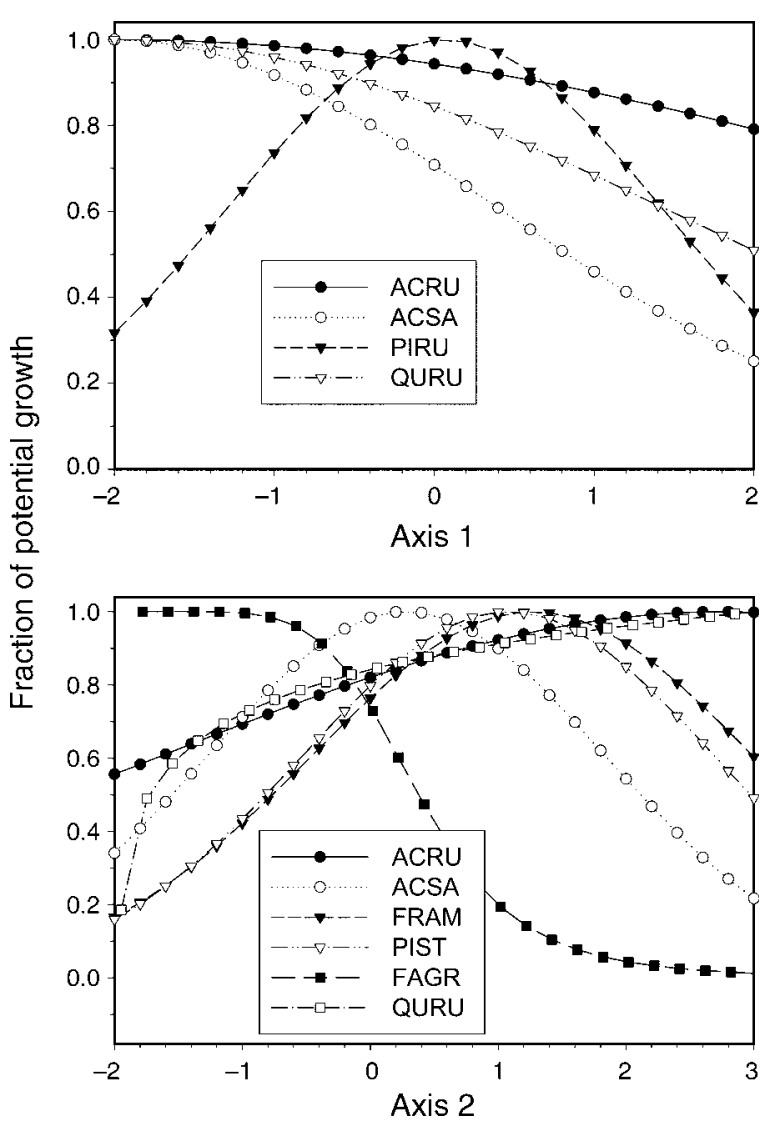

FIG. 2. Predicted variation in potential growth along the first two ordination axes for species in which the most parsimonious model included significant variation along one or both of the axes (Table 2). See Appendix for the estimated parameters of the corresponding functions. $\sim 18 \mathrm{~cm} \mathrm{dbh}$, with growth rates declining sharply in larger size classes (Fig. 4). This pattern is not unexpected for paper birch, which is distinctive among the 14 species for its short life span (Fowells 1965). In contrast, beech has one of the longest potential life spans of the 14 species. Beech populations throughout the region, however, have been subject to severe infestations of beech bark disease during the past 50 years (Houston 1994). The disease is most severe in large individuals (Twery and Patterson 1984), and our results may reflect the pervasive effects of the disease in northeastern forests.

\section{Effects of neighboring tree size and distance on competitive effect}

Models that ignored the effects of competition (the "No comp." model in Table 2) had dramatically worse $\mathrm{AIC}_{\mathrm{c}}$ scores than models that included the effects of competition (Table 2). The $\alpha$ parameter (Eq. 5) controls the effect of neighboring tree size on net competitive effect (NCI). Estimates of $\alpha$ for these 14 species ranged from 0 to 2.8 (mean 1.27; see Appendix). Tree biomass scales as roughly the square of $\mathrm{dbh}$ (e.g., Jenkins et al. 2003), so an estimated value of $\alpha \simeq 2$ indicates that competitive effect scales approximately linearly with neighboring plant biomass. Crown radius is approximately a linear function of $\mathrm{dbh}$ in north-temperate tree species (Canham et al. 1994, 1999), so values of $\alpha \simeq 1$ suggest that the effect of a neighbor is proportional to its crown radius. Values of $\alpha$ close to zero indicate that competitive effect scales with the density of neighbors, regardless of the size of individual trees, whereas values $\gg 2$ indicate that neighbors have an effect that is disproportionately large relative to their biomass. Estimated values for $\alpha$ were very low for three species 

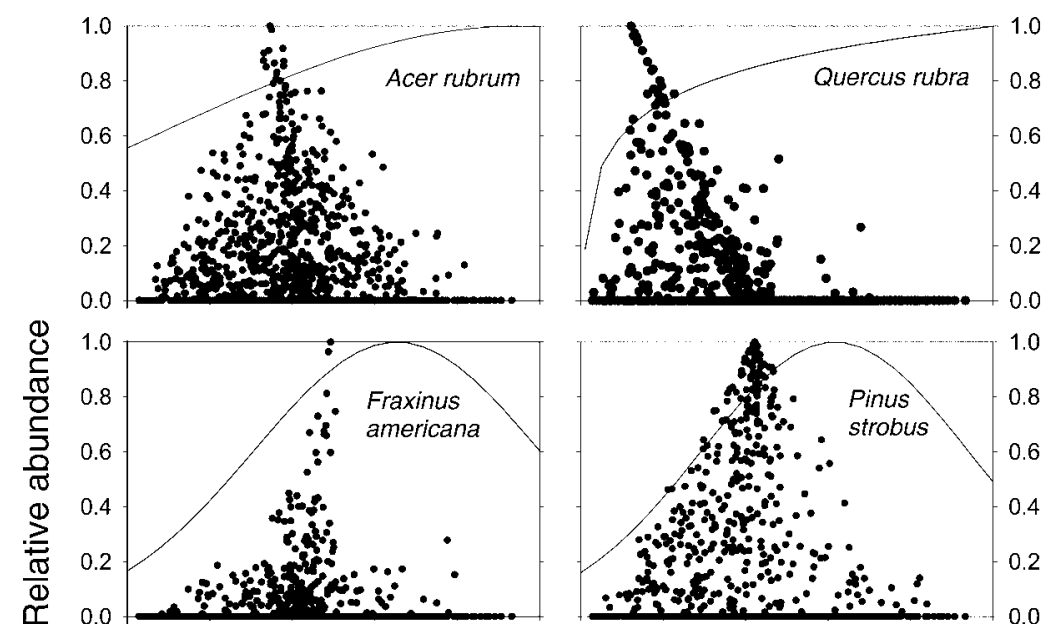

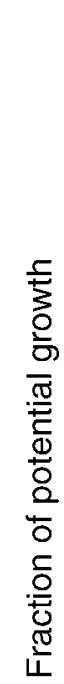
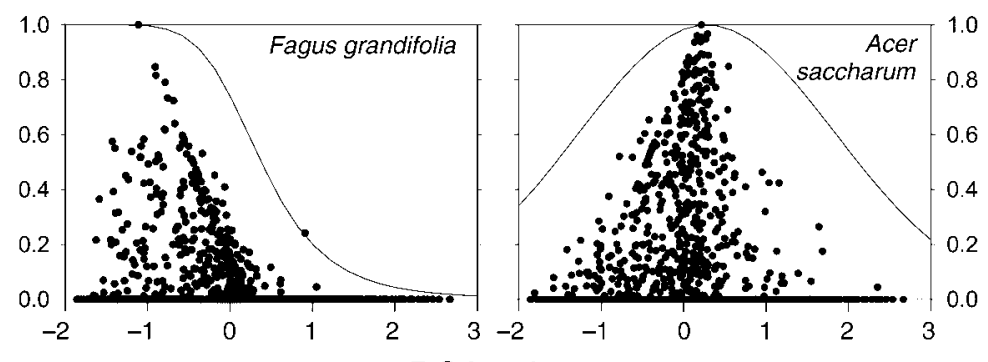

\section{Low fertility}

High fertility

FIG. 3. Relative abundance of six tree species in the full data set of 1249 plots (solid circles, using relative basal area in the most recent census data as an estimate of abundance), and the fraction of potential growth (solid line, in the absence of competition, and at the tree size that was optimal for growth), as a function of the position of the plot along the second ordination axis.

(balsam fir, yellow birch, and eastern hemlock), whereas only one species (sweet birch) had a value $\gg 2$. Estimates of $\alpha$ for neighbors of the remaining eight species showed a gradation from values slightly less than 1 (e.g., beech and trembling aspen) to slightly greater than 2 (eastern white pine).

The $\beta$ parameter (Eq. 5) controls the magnitude of the decline in effect of a neighbor with increasing distance from a target tree. The estimated $\beta$ values were all relatively low (maximum $\beta=0.66$ for eastern hemlock, mean for the 14 species $=0.33$ ), and were effectively zero for three species (white ash, trembling aspen, and black cherry; see Appendix). The three highest values of $\beta$ occurred for three conifer species with relatively narrow crowns (hemlock, red spruce, and balsam fir; Appendix). Values of $\sim 0.5$ would indicate that competitive effect of a neighbor declines as a function of the square root of distance. Because of plot size limitations, we cannot assess the effects of neighbors beyond a distance of $\sim 7.6$ $\mathrm{m}$. Our results indicate that the effect of a neighbor does not decline dramatically within distances of 7-8 m.

\section{Variation in sensitivity to competition as a function of species and size}

Our analyses indicate that growth declines as a simple negative exponential function of increasing NCI for all species except black birch, for which the decline was slightly sigmoidal (Fig. 5). Sensitivity to crowding varied dramatically among the 14 species (Fig. 5). For 30-cm target trees, growth under the maximum observed relative crowding (i.e., $\mathrm{NCI}=1$ ) ranged from a low of $7.8 \%$ of potential growth in paper birch to a high of $57.8 \%$ in trembling aspen (Fig. 5B). There was no obvious relationship between shade tolerance and sensitivity to competition (Fig. 5). There was, however, evidence of variation in sensitivity to the effects of competition as a function of target tree size for eight of the 14 species (i.e., $\gamma \neq 0$; Appendix). In all eight cases, smaller trees were much more sensitive to competition than larger trees $(-2.0<\gamma<-0.9$; Appendix $)$. Among smaller trees of the eight species, the least sensitive were the three most shade-tolerant species (balsam fir, beech, and eastern hemlock). The six species for which there was no evidence of an effect of target tree size on response to competition ranged from very shade tolerant (e.g., sugar maple) to very intolerant (e.g., paper birch). As a result, the rankings of sensitivity to competition among the 14 species and the absolute magnitude of reduction in growth as a function of crowding varied dramatically from small to large stems. For $15 \mathrm{~cm} \mathrm{dbh}$ stems under the maximum observed relative crowding (i.e., $\mathrm{NCI}=1$ ), observed growth was reduced to only 


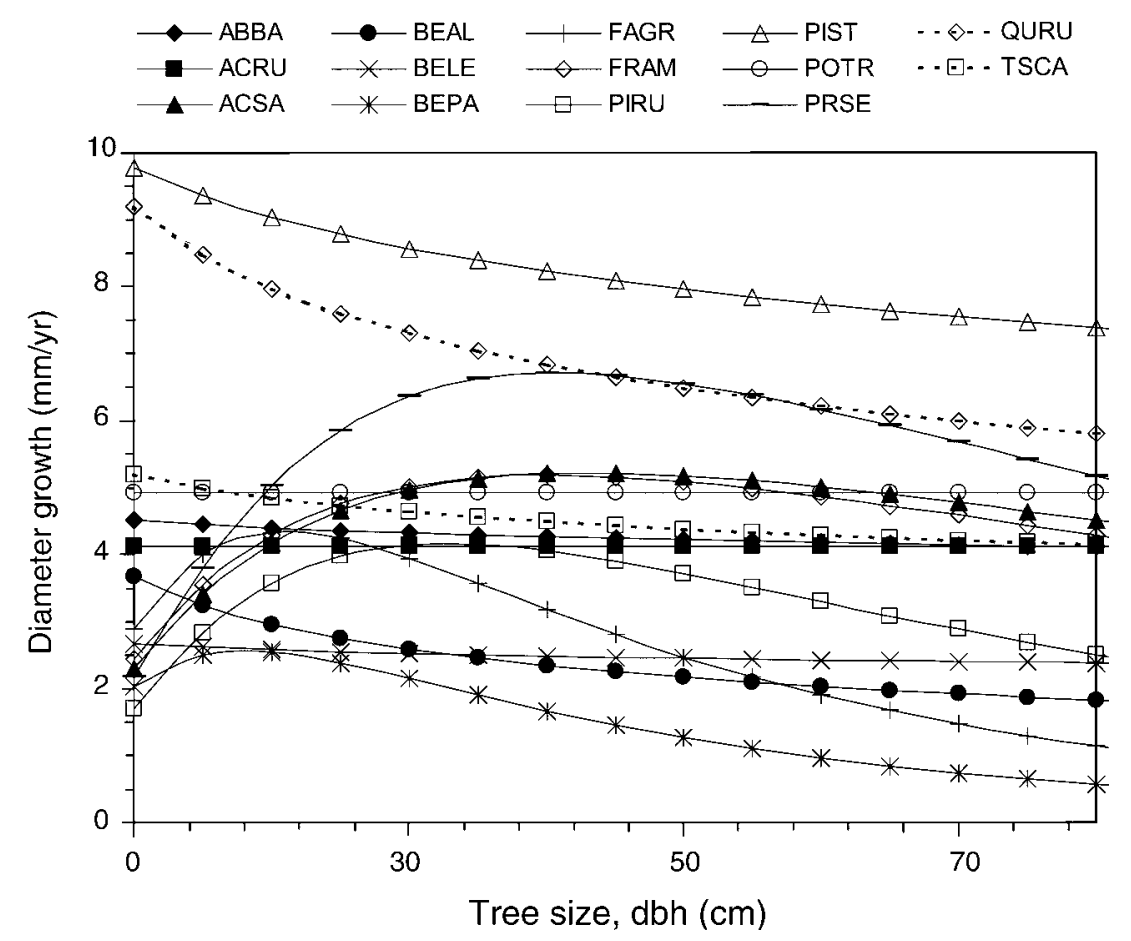

FIG. 4. Predicted effects of variation in target tree size (dbh) on potential diameter growth (i.e., in the optimal site, and in the absence of competition). See Appendix for the estimated parameters for the corresponding functions. See Table 1 for key to species abbreviations.

$1.4-46.7 \%$ of potential (Fig. 5A), and white pine, eastern hemlock, and paper birch were the three species most sensitive to crowding. For $60 \mathrm{~cm} \mathrm{dbh} \mathrm{stems,} \mathrm{predicted}$ growth under maximum crowding ranged from $7.7 \%$ to $87.2 \%$ of potential (Fig. 5C), and paper birch, black cherry, and sugar maple were the three species with the greatest reduction in growth. This ontogenetic shifting of competitive hierarchies illustrates some of the complexities and challenges inherent to the management of uneven-aged stands.

\section{Intra- and interspecific variation in competitive effects}

For all target species except red spruce, our results lead us to reject the hypothesis that all species of competitors have equivalent effects (Table 2). For red spruce, the model that grouped all species of competitors as equivalent was a better fit to the data than models that discriminated between at least some species of competitors (Table 2). For all of the remaining 13 species except white ash, the "mixed" model that discriminated between intraspecific competition and three groups of interspecific competitors ("weak," "intermediate," and "strong" competitors: $\lambda=0-0.33$, $0.33-0.66$, and $0.66-1.0$, respectively, based on the individual competition coefficients given in Table 3) was the most parsimonious of the four alternate models that differed in the grouping of species of competitors. For white ash, a simpler model that grouped all species of interspecific competitors vs. intraspecific competitors was slightly better than the mixed model (Table 2).

We used the species-specific competition indices estimated in the "full" model (Table 3) to explore whether the strength of competition between any two species and the Euclidian distance between the centroids for the two species in the DCA ordination (i.e., a measure of the dissimilarity in distribution of the species along environmental gradients) were related. Specifically, for each of the 11 species for which there were more than five estimated competition coefficients for neighboring species, we calculated product-moment correlations between the competition coefficients and the ordination distance between the target species and the neighbor species. Seven of the 11 correlations were negative and four were positive, but none of the correlations was significant at $P<0.05$. Thus, our results provide very little evidence that the strength of competition between two species varied as a function of the distribution of the species within the ordination.

We also examined the mean distances to neighbors of different species within a plot, to explore whether the competition coefficients might be influenced by spatial segregation of species (Freckleton and Watkinson 2001, Turnbull et al. 2004). In general, the mean distances to neighbors of different species were remarkably similar for all target species (data not presented). There does not appear to be any evidence that very low competitive 

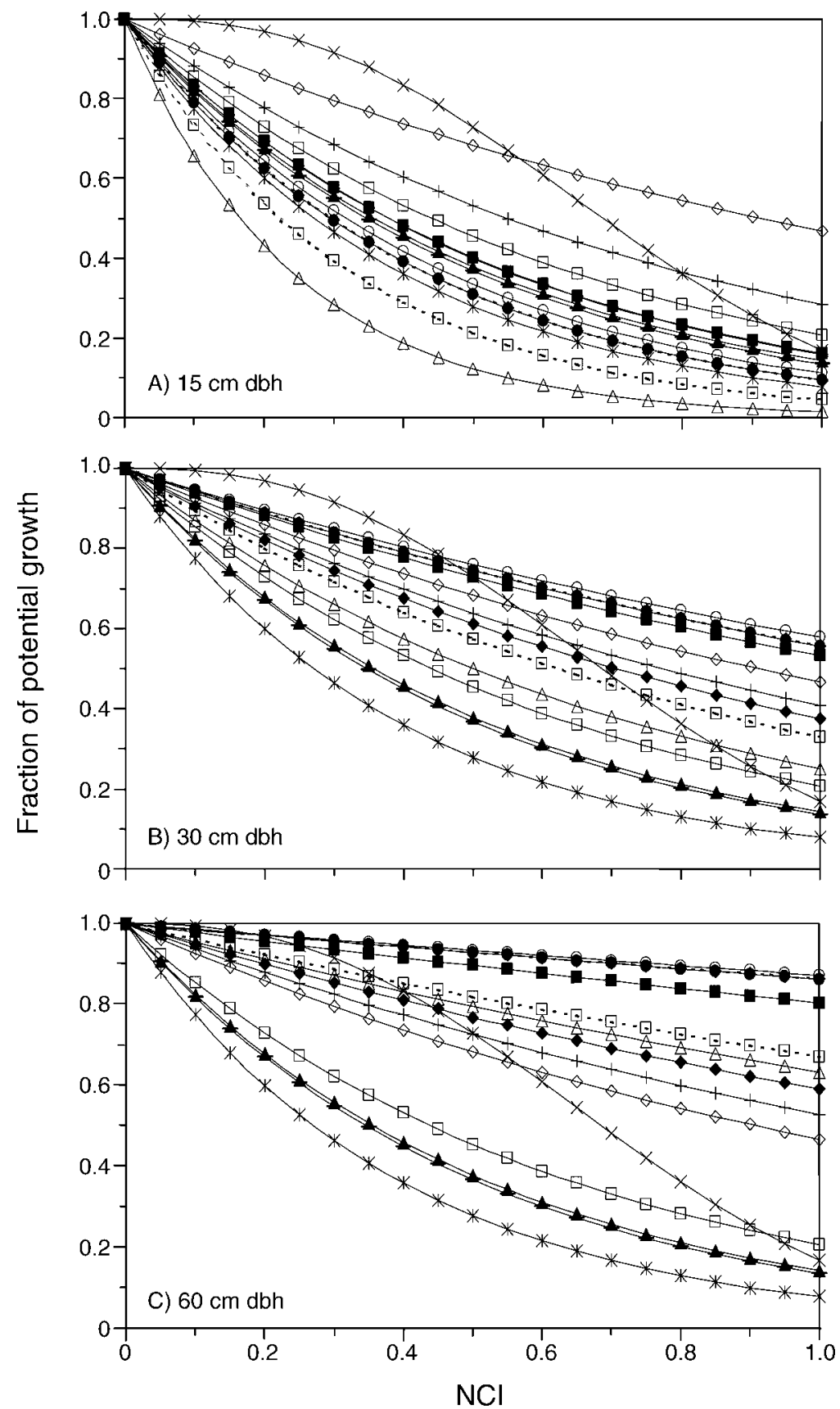

FIG. 5. Predicted effects of variation in NCI (neighborhood crowding index) on growth for trees of 15, 30, and $60 \mathrm{~cm} \mathrm{dbh}$. For each species, NCI is relative to the target tree with the highest value of NCI (Eq. 5). See Appendix for the estimated parameters of the corresponding exponential functions. For a key to the symbols, see Fig. 4.

effects of a particular neighbor species on a particular target species are due to spatial segregation of the species within a plot (i.e., that the neighbor species with low competitive effects are distinctively far away from targets). This result parallels the estimation of Turnbull et al. (2004) of the effects of spatial segregation on competitive interactions among annuals in a limestone grassland.
For all of the 14 target species, conspecifics were the most common neighbors, ranging from a low of $15 \%$ to a high of $65 \%$ of all neighbors for a given target species (mean $37.4 \%$ of neighbors). There was no obvious correlation between the percentage of neighbors that were conspecific and the estimated strength of intraspecific competition (which was usually strong, regardless of whether a species was more or less likely to have 
TABLE 3. Per capita competition coefficients $\left(\lambda_{i, z}\right)$ estimated from the full model for the effects of a neighbor of species $i$ on target species $z$ for the 11 species for which at least five species of competitors were common enough for parameter estimation.

\begin{tabular}{|c|c|c|c|c|c|c|c|c|c|c|c|}
\hline \multirow[b]{2}{*}{ On ... } & \multicolumn{11}{|c|}{ Effect of ... } \\
\hline & FAGR & TSCA & ACSA & PIRU & ABBA & BEAL & ACRU & FRAM & QURU & PIST & BEPA \\
\hline FAGR & $\underline{0.72}$ & 1.00 & 0.42 & & & 0.56 & 0.45 & 0.45 & 0.64 & & 0.45 \\
\hline TSCA & $\overline{0.50}$ & $\underline{0.44}$ & 0.28 & 0.30 & 0.94 & 0.08 & 0.10 & & 0.35 & 0.25 & 0.15 \\
\hline ACSA & 0.80 & 0.69 & $\underline{1.00}$ & 0.39 & 0.90 & 0.62 & 0.01 & 0.56 & 0.64 & 0.06 & 0.63 \\
\hline PIRU & & 0.49 & 1.00 & $\underline{0.68}$ & 0.41 & 0.74 & 0.82 & & & 0.38 & 0.47 \\
\hline ABBA & & 0.43 & 1.00 & 0.26 & $\underline{0.09}$ & 0.45 & 0.53 & & & 0.21 & 0.70 \\
\hline BEAL & 0.18 & 0.65 & 0.02 & 0.85 & 0.43 & $\underline{0.79}$ & 0.56 & 0.00 & & & 1.00 \\
\hline ACRU & 0.58 & 0.38 & 0.78 & 0.55 & 0.64 & $\overline{0.51}$ & $\underline{0.47}$ & 0.09 & 1.00 & 0.00 & 0.43 \\
\hline FRAM & 0.00 & 0.21 & 0.04 & 0.00 & & 0.01 & 0.68 & $\underline{1.00}$ & & 0.00 & \\
\hline QURU & 0.57 & 0.56 & 1.00 & & & & 0.01 & $\overline{0.84}$ & $\underline{0.97}$ & 0.00 & 0.15 \\
\hline PIST & & 0.02 & 0.98 & 0.02 & 0.31 & & 0.79 & 0.98 & 0.99 & $\underline{0.87}$ & 0.94 \\
\hline BEPA & 0.20 & 0.55 & 0.27 & 0.04 & 1.00 & 0.00 & 0.00 & 0.75 & 1.00 & $\overline{0.00}$ & $\underline{0.47}$ \\
\hline Mean & 0.45 & 0.49 & 0.62 & 0.34 & 0.59 & 0.42 & 0.40 & 0.58 & 0.80 & 0.20 & 0.54 \\
\hline
\end{tabular}

Notes: Cells are blank if there were not enough neighbors of that species to estimate a coefficient from the model. The species are ordered approximately from most to least shade tolerant from top left to bottom right. Intraspecific competition coefficients (underlined) are shown along the diagonal. Strong interactions $(>0.8)$ are shown in boldface. Weak interactions $(<0.2)$ are shown in italics. The competition coefficients are scaled so that the strongest competitor for each target species has a value of 1.0. Also shown are the mean competitive effects of each of the 11 species on all target tree species for which it was a common neighbor. The bottom row of the table contains the mean of the estimated effects of a given species on the different species of neighbors (including intraspecific competition).

conspecifics as neighbors). Thus, even though intraspecific competition was usually quite strong and conspecifics were usually the dominant neighbors, the variation among target species in the strength of intraspecific competition was not related to the likelihood that a neighbor was a conspecific.

Table 3 presents the matrix of pairwise competition coefficients for the 11 most common tree species. Note that species are ordered approximately from most to least shade tolerant. Twenty of the 121 elements (17\%) of the matrix could not be estimated because of insufficient numbers of neighbors. Of the estimated interspecific competition coefficients (i.e., the nondiagonal elements), $25 \%$ were relatively weak interactions ( $\lambda$ $\leq 0.2 ; 23$ of 91 interspecific coefficients) relative to the strongest pairwise competitive interaction, whereas $20 \%$ were strong interactions ( $\lambda \geq 0.8 ; 18$ of 91 coefficients) (Table 3). Sugar maple stands out as a species with strong competitive effects on the most other target species (four species), whereas red oak had the highest mean competitive effect across all target species (for which there were sufficient neighbors to calculate a coefficient). Eastern white pine had the lowest average competitive effect on other target tree species (mean interspecific $\lambda=0.20$ ). In general, the strong interspecific interactions were near the diagonal, i.e., between species with very similar shade tolerance (11 of 18 strong interspecific interactions were within two elements above or below the diagonal). Weak interspecific interactions were generally away from the diagonal, i.e., between species with very different shade tolerance (18 of 23 weak interspecific interactions were more than two elements away from the diagonal).

Most of the individual pairwise interactions were strongly asymmetric (i.e., the effect of species A on B was much larger or smaller than the effect of B on A). If the magnitude of the asymmetry is used as a basis for ranking potential competitive dominance, then there is a clear competitive hierarchy among the four most shadetolerant species, with hemlock $>$ beech $>$ sugar maple $>$ red spruce. Among the shade-intolerant species, there was also a set of species with a clear competitive hierarchy: red oak $>$ paper birch $>$ red maple $>$ white pine. The relatively weak competitive effects of red maple on other species (Table 3) were surprising, given its status as one of the most common tree species in the data set, and indeed, across much of the northeastern U.S. (Abrams 1998).

\section{Predictive power and methodological issues}

Our approach exploits natural variation in canopy structure (due to processes including natural and human disturbance, and land-use history) to sample variation in neighborhood configuration. One of the benefits of the large number and stratified random distribution of the FIA plots is that our sample contains a very wide range of mixtures of species and sizes of trees, across a very wide range of site conditions. The major limitation of the current FIA plot design (for our purposes) is the relatively small size of the plots. This limits the radius within which neighbors can be included in the model. Our previous studies with adult trees in both temperate and tropical forests (Canham et al. 2004, Uriarte et al. 2004b) used larger plots and estimated the effective neighborhood radius for each species of target tree (i.e., empirically determined the radius beyond which inclusion of neighbors did not improve the likelihood of the model). Effective neighborhood radii in those two studies ranged from 3.2 to $19.8 \mathrm{~m}$, but the effect of neighbors declined significantly with distance (Canham et al. 2004, Uriarte et al. 2004b). The maximum neighborhood radius of $7.58 \mathrm{~m}$ allowed by the FIA plot 
design thus captures the bulk of the competitive effect of neighbors, but almost certainly fails to include the effects of some competitors. This problem is probably most severe for very large target trees that may dominate the plot. The limitation of a finite mapping of local neighborhoods is a common constraint in any neighborhood analysis, whether the analysis focuses on tree growth, seed rain, or leaf litterfall (Canham and Uriarte 2006).

Although all of the models produced unbiased estimates of growth (i.e., slopes of predicted vs. observed growth were all very close to 1.0), the goodness of fit of the models was relatively low, with $R^{2}$ ranging from 0.125 for red maple to 0.351 for white pine (Table 2). The variance in predicted growth increased as a linear function of predicted growth, with a slope ranging from 0.424 in black birch to 1.287 in white pine (mean value of $\varepsilon_{1}=0.738$ for the 14 species; Appendix). This is a common observation in studies of tree growth (Pacala et al. 1994, Canham et al. 2004). There are many sources of potential error, including both process and measurement error. From a biological perspective, one interpretation of the increase in variance with the mean is that as expected growth increases due to a relaxing of constraints due to plant size, local site conditions, or competition, other factors not accounted for in the model increasingly come into play. These factors may include pests, pathogens, physical damage, and the residual effects of past suppression and release (Wright et al. 2000). The uncertainty in predicted growth has important implications from both a theoretical and a management perspective (Clark et al. 2003, Canham et al. 2004).

\section{Implications for theories of forest community organization}

Our results reveal strong asymmetries in competitive interactions among tree species in these temperate forests (Table 3) and clear evidence, for all but one of the species, that different species of neighbors have strikingly different competitive effects. These results are in sharp contrast to the neutral model of species interactions in tropical forests proposed by Hubbell (2001). We have recently tested for equivalence of competitive effects in two dominant species from a temperate coniferous forest (British Columbia; Canham et al. 2004), the 12 most abundant species in a moderately species-rich tropical forest (Puerto Rico; Uriarte et al. 2004b), and saplings of 60 tree species in a species-rich tropical forest (Barro Colorado Island, Panama; Uriarte et al. 2004a). In the most species-rich system (Panama), the most parsimonious model for over half of the target species treated all species of neighbors as equivalent. In the other two less species-rich systems (Puerto Rico and British Columbia), there was strong evidence that different species of neighbors were not equivalent in their effects on essentially all target tree species. There are a number of possible interpretations for this pattern. Perhaps the most obvious is simply a methodological limitation: the numbers of neighbors of any single species is relatively low in the most speciesrich system. This may limit the power of the models to detect interspecific differences in competitive effects simply because of insufficient numbers of neighbors of a given species. A second potential reason is the relative uniformity of neighborhood structure in Panamanian tropical forests in comparison with the other sites.

Our results also address, at least by inference, the effects of competitive interactions on the distribution of tree species along environmental gradients and the magnitude of the displacement (if any) of the realized niches from the fundamental niches of forest trees (Loehle 2000). Specifically, they allow us to estimate the variation in potential growth of tree species (in the absence of competition) along ordination axes defined by the relative abundance of species (Fig. 3). The results indicate that shade-tolerant species generally have their highest potential growth in the same sites where they reach their greatest relative abundance, whereas a number of the less shade-tolerant species show a clear displacement between maximum relative abundance and maximum potential growth, suggesting a displacement of their realized niches from their sites of optimal growth (Fig. 3).

\section{Implications for development of sustainable forestry}

Landowners and foresters now routinely manage for complex residual structure in northeastern forests. Our results suggest that timber yield following selective logging will vary dramatically depending on the configuration of the residual canopy, because of the dramatic interspecific variation in the magnitude of both the competitive effects of different species of neighbors and the competitive responses of different species of target trees to neighbors. The strong asymmetries in the matrix of competition coefficients and the reasonably large number of weak competition coefficients (Table 3) suggest that there may be considerable benefit in managing for particular mixtures of species within a given neighborhood: in effect, managing for patchiness not only in canopy structure (Coates et al. 2003), but also in canopy composition. For example, the matrix of competition coefficients (Table 3) suggests that there are clear benefits of managing for mixtures of successional status within a given neighborhood, because the strongest competitive interactions (e.g., higher competitive coefficients) tended to be between species of similar shade tolerance (Table 3 ).

The long-term consequences of any given partial harvest will be a function of both the immediate configuration of the residual stand and the subsequent differential growth of residual trees. The long-term effect on trees $\mathrm{A}$ and $\mathrm{B}$ of removing tree $\mathrm{C}$ will depend not only on the response of $\mathrm{A}$ and $\mathrm{B}$ to the immediate release from the competitive effects of $\mathrm{C}$, but also on the subsequent shift in the competitive balance between $\mathrm{A}$ and $\mathrm{B}$ as they respond differentially to the removal of $\mathrm{C}$. 
Predicting these long-term, indirect effects of partial harvesting requires that empirical analyses (models) of the sort we have presented here be embedded in a simulation model of forest dynamics such as SORTIE (Coates et al. 2003). This has been a specific goal of our research, and played a part in many of our decisions about the balance of complexity and phenomenology that was appropriate for these analyses. The FIA data sets are an extraordinary resource and certainly may be used for much more complex and mechanistic analyses of canopy tree competition than those presented here. Nonetheless, the benefits of simplicity in simulation models provide a compelling argument for simplicity in the empirical analyses that make up the components of those models.

\section{ACKNOWLEDGMEnTs}

We thank the USDA Forest Service, Forest Inventory and Analysis program for providing an extraordinary resource for ecological research. This material is based upon work supported, in part, by the National Science Foundation under Grant Number 0087214. This research is a contribution to the Institute of Ecosystem Studies.

\section{Literature Cited}

Abrams, M. D. 1998. The red maple paradox. BioScience 48: 355-364.

Austin, M. P., and T. M. Smith. 1989. A new model for the continuum concept. Vegetatio 83:35-47.

Beaudet, M., C. Messier, and C. D. Canham. 2002. Predictions of understory light conditions in northern hardwood forests following parameterization, sensitivity analysis, and tests of the SORTIE light model. Forest Ecology and Management 165(1-3):231-244.

Bella, I. E. 1971. A new competition model for individual trees. Forest Science 17:364-372.

Berger, U., and H. Hildenbrandt. 2000. A new approach to spatially explicit modelling of forest dynamics: spacing, ageing and neighbourhood competition in mangrove trees. Ecological Modelling 132:287-302.

Bigelow, S. W., and C. D. Canham. 2002. Edaphic effects on growth and distribution of juvenile canopy trees in northeastern USA. Journal of Ecology 90:188-200.

Biging, G. S., and M. Dobbertin. 1992. A comparison of distance-dependent competition measures for height and basal area growth of individual conifer trees. Forest Science 38:695-720.

Biging, G. S., and M. Dobbertin. 1995. Evaluation of competition indices in individual tree growth models. Forest Science 41:360-377.

Borland Software. 2000. Delphi for Windows. Version 6. Borland Software, Cuperino, California, USA.

Burnham, K. P., and D. R. Anderson. 2002. Model selection and multimodel inference: a practical information-theoretic approach. Second edition. Springer-Verlag, New York, New York, USA.

Canham, C. D., K. D. Coates, P. Bartemucci, and S. Quaglia. 1999. Measurement and modeling of spatially-explicit variation in light transmission through interior cedar-hemlock forests of British Columbia. Canadian Journal of Forest Research 29:1775-1783.

Canham, C. D., A. C. Finzi, S. W. Pacala, and D. H. Burbank. 1994. Causes and consequences of resource heterogeneity in forests: Interspecific variation in light transmission by canopy trees. Canadian Journal of Forest Research 24:337-349.

Canham, C. D., P. T. LePage, and K. D. Coates. 2004. A neighborhood analysis of canopy tree competition: effects of shading versus crowding. Canadian Journal of Forest Research 34:778-787.

Canham, C. D., and M. Uriarte. 2006. Analysis of neighborhood dynamics of forest ecosystems using likelihood methods and modeling. Ecological Applications 16, in press.

Caspersen J. P., S. W. Pacala, J. C. Jenkins, G. C. Hurtt, P. R. Moorcroft, and R. A. Birdsey. 2000. Contributions of landuse history to carbon accumulation in US forests. Science 290:1148-1151.

Clark, J. S., J. Mohan, M. Dietze, and I. Ibanez. 2003. Coexistence: how to identify trophic trade-offs. Ecology 84: $17-31$.

Clark, J. S., M. Silman, R. Kern, E. Macklin, and J. HilleRisLambers. 1999. Seed dispersal near and far: patterns across temperate and tropical forests. Ecology 80:1475-1494.

Coates, K. D., C. Messier, M. Beaudet, D. L. Sachs, and C. D. Canham. 2003. Use of a spatially explicit individual-tree model (SORTIE-BC) to explore the implications of patchiness in structurally complex forests. Forest Ecology and Management 186:297-310.

Curtis, J. T. 1959. The vegetation of Wisconsin. University of Wisconsin Press, Madison, Wisconsin, USA.

Edwards, A. W. F. 1992. Likelihood. Johns Hopkins University Press, Baltimore, Maryland, USA.

Foli, E. G., D. Alder, H. G. Miller, and M. D. Swaine. 2003. Modelling growing space requirements for some tropical forest tree species. Forest Ecology and Management 173:7988.

Fowells, H. A. 1965. Silvics of forest trees of the United States. USDA Forest Service Agricultural Handbook Number 271, Washington, D.C., USA.

Freckleton, R. P., and A. R. Watkinson. 2001. Predicting competition coefficients for plant mixtures: reciprocity, transitivity and correlation with life history traits. Ecology Letters 4:348-357.

Gauch, H. G., Jr. 1982. Multivariate analysis and community structure. Cambridge University Press, Cambridge, UK.

Goffe, W. L., G. D. Ferrier, and J. Rogers. 1994. Global optimization of statistical functions with simulated annealing. Journal of Econometrics 60:65-99.

Goldberg, D. E. 1990. Components of resource competition in plant communities. Pages 27-49 in J. B. Grace and D. Tilman, editors. Perspectives in plant competition. Academic Press, New York, New York, USA.

Goldberg, D. E., and K. Landa. 1991. Competitive effect and response: hierarchies and correlated traits. Pages 281-290 in J. Silvertown, M. Franco, and J. L. Harper, editors. Plant life histories: ecology, phylogeny and evolution. Cambridge University Press, Cambridge, UK.

Goodale, C. L., K. Lajtha, K. J. Nadelhoffer, E. W. Boyer, and N. A. Jaworski. 2002. Forest nitrogen sinks in large eastern U.S. watersheds: estimates from forest inventory and an ecosystem model. Biogeochemistry 57/58:239-266.

Grubb, P. J. 1977. Maintenance of species-richness in plant communities: importance of regeneration niche. Biological Reviews of the Cambridge Philosophical Society 52:107-145.

Harvey, B. D., A. Leduc, S. Gauthier, and Y. Bergeron. 2002. Stand-landscape integration in natural disturbance-based management of the southern boreal forest. Forest Ecology and Management 155(1-3):369-385.

He, F., and R. P. Duncan. 2000. Density-dependent effects on tree survival in an old-growth Douglas-fir forest. Journal of Ecology 88:676-688.

Hegyi, F. 1974. A simulation model for managing jack-pine stands. Pages 74-90 in J. Fries, editor. Growth models for tree and stand simulation. Royal College of Forestry, Stockholm, Sweden.

Hilborn, R., and M. Mangel. 1997. The ecological detective: confronting models with data. Princeton University Press, Princeton, New Jersey, USA. 
Hill, M. O. 1979. DECORANA: A FORTRAN program for detrended correspondence analysis and reciprocal averaging. Cornell University Press, Ithaca, New York, USA.

Houston, D. R. 1994. Major new tree disease epidemics: beech bark disease. Annual Review of Phytopathology 32:75-87.

Howard, T. G., and D. E. Goldberg. 2001. Competitive response hierarchies for germination, growth, and survival and their influence on abundance. Ecology 82:979-990.

Hubbell, S. P. 2001. The unified neutral theory of biodiversity and biogeography. Monographs in Population Biology Number 32. Princeton University Press, Princeton, New Jersey, USA.

Jenkins, J. C., R. A. Birdsey, and Y. Pan. 2001. Biomass and NPP estimation for the mid-Atlantic region (USA) using plot-level forest inventory data. Ecological Applications 11: 1174-1193.

Jenkins, J. C., D. C. Chojnacky, L. S. Heath, and R. A. Birdsey. 2003. National-scale biomass estimators for United States tree species. Forest Science 49:12-35.

Johnson, J. B., and K. S. Omland. 2004. Model selection in ecology and evolution. Trends in Ecology and Evolution 19: 101-108.

Keddy, P. A. 1989. Competition. Chapman and Hall, London, UK.

Knapp, L. B., and C. D. Canham. 2000. Invasion of old-growth forests by Ailanthus altissima: sapling growth and recruitment in canopy gaps. Journal of the Torrey Botanical Society 127: 307-315.

Kobe, R. K. 1996. Intraspecific variation in sapling mortality and growth predicts geographic variation in forest composition. Ecological Monographs 66:181-201.

Kobe, R. K., S. W. Pacala, J. A. Silander, Jr., and C. D. Canham. 1995. Juvenile tree survivorship as a component of shade tolerance. Ecological Applications 5:517-532.

Larocque, G. R. 2002. Examining different concepts for the development of a distance-dependent competition model for red pine diameter growth using long-term stand data differing in initial stand density. Forest Science 48:24-34.

Loehle, C. 2000. Forest ecotone response to climate change: sensitivity to temperature response functional forms. Canadian Journal of Forest Research 30:1632-1645.

Lorimer, C. G. 1983. Test of age-independent competition indices for individual trees in natural hardwood stands. Forest Ecology and Management 6:343-360.

Mitchell, S. J., and W. J. Beese. 2002. The retention system: reconciling variable retention with the principles of silvicultural systems. Forestry Chronicle 78:397-403.

Pacala, S. W., C. D. Canham, J. Saponara, J. A. Silander, Jr., R. K. Kobe, and E. Ribbens. 1996. Forest models defined by field measurements: estimation, error analysis and dynamics. Ecological Monographs 66:1-43.

Pacala, S. W., C. D. Canham, J. A. Silander, Jr., and R. K. Kobe. 1994. Sapling growth as a function of resources in a north temperate forest. Canadian Journal of Forest Research 24:2172-2183.

Ribbens, E., J. A. Silander, and S. W. Pacala. 1994. Seedling recruitment in forests: calibrating models to predict patterns of tree seedling dispersion. Ecology 75:1794-1806.

Turnbull, L. A., D. Coomes, A. Hector, and M. Rees. 2004. Seed mass and the competition/colonization trade-off: competitive interactions and spatial patterns in a guild of annual plants. Journal of Ecology 92:97-109.

Twery, M. J., and W. A. Patterson. 1984. Variation in beech bark disease and its effects on species composition and structure of northern hardwood stands in central New England. Canadian Journal of Forest Research 14:565-574.

Uriarte, M., R. Condit, C. D. Canham, and S. P. Hubbell. 2004a. A spatially-explicit model of sapling growth in a tropical forest: Does the identity of neighbours matter? Journal of Ecology 92:348-360.

Uriarte, M., C. D. Canham, J. Thompson, and J. K. Zimmerman. 2004b. A neighborhood analysis of tree growth and survival in a hurricane-driven tropical forest. Ecological Monographs 74:591-614.

USDA (U.S. Department of Agriculture) Forest Service. 2001. 2000 RPA assessment of forest and range lands. FS687, USDA Forest Service, Washington, D.C., USA.

van Breemen, N., A. F. Finzi, and C. D. Canham. 1997. Canopy tree-soil interactions within temperate forests: effects of fine-scale variation in soil texture and elemental composition on species distributions. Canadian Journal of Forest Research 27:1110-1116.

Vettenranta, J. 1999. Distance-dependent models for predicting the development of mixed coniferous forests in Finland. Silva Fennica 33:51-72.

Wagner, R.G., and S. R. Radosevich. 1998. Neighborhood approach for quantifying interspecific competition in coastal Oregon forests. Ecological Applications 8:779-794.

Whittaker, R. H. 1975. Communities and ecosystems. Second edition. MacMillan, New York, New York, USA.

Wimberly, M. C., and B. B. Bare. 1996. Distance-dependent and distance-independent models of Douglas-fir and western hemlock basal area growth following silvicultural treatment. Forest Ecology and Management 89:1-11.

Wright, E. F., C. D. Canham, and K. D. Coates. 2000. Effects of suppression and release on sapling growth for eleven tree species of northern, interior British Columbia. Canadian Journal of Forest Research 30:1571-1580.

\section{APPENDIX}

Tables reporting parameter estimates and two-unit support intervals for the most parsimonious models for each of the 14 target tree species (Ecological Archives A016-023-A1). 